\title{
(2) \\ Living Grass Irrigation Ditches in Traditional Portuguese Agriculture: Autecology in the study of ethnobotany
}

Research

George F. Estabrook

\begin{abstract}
Over the past decades, increasing numbers of scholarly works recognize the importance of plant ecology in understanding human history, culture, and technology. These works represent a wide variety of disciplines including ecological history, human geography, ecological agriculture, economic botany, conservation biology, human ecology, ecological anthropology, and ethnobotany. I believe that these disciplines differ among themselves with respect to the training, traditions, styles, points of view, and data sources, more than they do with respect to the questions they seek to answer. Consideration of plant ecology by each of these disciplines has brought their questions and the kinds of answers they might consider even closer, without substantially diminishing other differences among them.
\end{abstract}

The goals of this essay are: 1 . To present, briefly, an historical overview of the concepts of the science of ecology, and to identify the place of autecology in the spectrum of subfields of modern scientific ecology; 2 . to suggest how the perspective of autecology might enrich ethnobotanical studies; 3 . to illustrate the perspective of autecology with some of my own work on the traditional agricultural technology of Portuguese peasants; and 4. to conclude with four points, made evident by the perspective of autecology in this illustration: a. The power of an ecological approach to ethnobotany; b. the legitimacy of plant-human interactions as a subject of ecological study; c. the utility of studying traditional cultures that have been invaded and contaminated by modern practices; and $d$. the role of culture in the instruction, practice and preservation of technology.

\section{Historical View of Ecology}

At present, disciplines outside of biology often use the term "ecology" to indicate reverence toward or protection of nature (Johnston et al. 1994). Biologists, however, define "ecology" as the scientific study of the interactions that determine the distribution and abundance of kinds of organisms. The term "ecology" is often attributed to Ernst Haeckel, a German zoologist who applied it in the late 19th century to the study of the relationship between animals and their environment (Krebs 1972). Soon, two journals to report the results of ecological studies were founded: The Journal of Ecology in 1912, and Ecology in 1918. By this time, the term "ecology" was applied equally to the study of plants, animals, or any other kind of organism. By the mid century, two sub-disciplines were recognized: Synecology, which studied biotic (involving other living organisms) interactions among different kinds of organisms; and autecology, which studied a single kind of organism, including its demography and its abiotic interactions with the physical or chemical environment (Daubenmire 1947).

For nearly a century the term "ecology" was known only to a few specialists, scarcely recognized by the rest of the academic world, and essentially unknown to the general public, until the coming of the environmental movement of

\section{Correspondence}

George F. Estabrook, Department of Ecology and Evolution, The University of Michigan, Ann Arbor, Michigan 48109-1048. U.S.A.

estabrook@umich.edu

Ethnobotany Research \& Applications 5:319-330 (2007) 
the late 1960's (Smith \& Smith 1998). Through the 1970's and 1980's, ecology diversified within the larger field of biology, and became better known to other disciplines and to the general public. The price of this popularization has been the diffusion of its meaning, so that now, outside of organismal biology and especially in the more social sciences and to the general public, the term "ecology" has connotations of environmentalism, i.e., preserve natural places, and be nice to other organisms. I suggest that this diffusion of the biological meaning of ecology has helped make it possible for environmental factors to be considered by a wider circle of scholars, many of whom who are now ready to enjoy the possible advantages of applying a more biological concept of ecology.

Within biology, ecology has diversified into a number of not entirely separate directions. Ecological agriculture applies ecology to solve problems in modern agriculture: Hoffman \& Carroll (1995) and Vandermeer (1995) provide excellent reviews, and the Crop Ecology text of Loomis \& Connor (1992) has become a standard reference of the field. Conservation Biology applies ecology to maintain organismal diversity (Goodland 1995). Ecosystem ecology seeks to explain the diversity and abundance of different kinds of organisms by studying the cycling of energy and material through various natural "compartments," such as living plants, water, soil, atmosphere, etc. Moran (1990) presents a collection of essays illustrating an ecosystems approach in anthropology, and I present an example of its application in ethnobotany (Estabrook 1998). Community ecology seeks to explain how aggregates of distinct plants and animals co-exist in the same place. Biotic interactions play an important role in these explanations. I have applied some of the scientific methods and concepts of community ecology to show that a fuel choice, explained in cultural terms by Portuguese peasant farmers, results in the maintenance of biodiversity in the heaths on which they depend (Estabrook 1994). Evolutionary ecology is the study of how or why some properties of plants or animals, which explain their presence and abundance, might have evolved. Salick (1995) discusses the potential for integrating evolutionary ecology into the study of economic botany.

Autecology, the study of how a single kind of organism makes its living in nature, is now distinguished into two subfields: Demography or population ecology, which is the study of the age structure and dynamics of the population of a single kind of organism, as mediated through birth, death, and migration; and physiological ecology, which is the study of how individual organisms survive and grow within the ranges of abiotic factors that they tolerate. Joyal (1994) presents a good example of a plant demography study in an ethnographic setting. Here, I will discuss the subfield of autecology that considers abiotic factors.

\section{Autecology in Ethnobotany}

An ecological approach to the study of how traditional people interact with plants (ethnobotany) endeavors to explain why plants are absent or present in particular places, and when they are present, why they are so abundant. The explanations sought belong to biological ecology, and so are not directly related to being nice to nature, nor to evoking natural laws to explain human history or behavior. An autecological approach seeks to explain the presence and relative abundance of a single kind of plant in particular places, using factors such as temperature, water, physical disturbance, light, fire, minerals, etc, especially if they are mediated by the plant's physiology or demography.

Ethnobotanical investigators have typically used a variety of techniques that include those of cultural anthropologists (interviewing and watching people); of historians (reading what other people have written in the past); and of archeologists and paleontologists (looking at artifacts, bones, or fossils of people in the past). Like the techniques of other natural sciences, those of autecology include both measurement and experiment, e.g., transplanting or environmental modifications that enable the comparison of observations. Some of the measurement technology available today is quite sophisticated, enabling quantitative descriptions of a wide variety of potentially relevant factors. For example, I used gas spectrophotometry to analyze the mineral contents of plants, and chemical techniques to analyze the mineral content, acidity and ion exchange capacity of soil, to help explain how the activities of Portuguese peasants result in the maintenance of the fertility of the soil in the terraces that they cultivate (Estabrook 1998). But less sophisticated, carefully made visual observations can be very useful as well.

However, what we seek to explain and how we explain it, not measurement technology, defines a field of scholarship. Thus, I believe that the familiarity and safety that attends staying within one's original field of scholarship, and not limited access to technology, has slowed the application of biological ecology in ethnobotany, economic botany and cultural anthropology. Another possible reason why studies in these fields have rarely been approached with an explicit autecological point of view is that the presence of a particular kind of plant is often taken as a given. Furthermore, the traditional practices that have created, or that maintain, the presence of that particular kind of plant may have been so completely incorporated into the culture under study that they have become invisible as technology. In this case, even the local informants will not be able to describe them as technology (Estabrook 1994).

Even though awareness of ecology is growing in studies of human history, culture, and technology as it relates to plants, it does so, at present, largely in the broader sense 


\section{Estabrook - Living Grass Irrigation Ditches in Traditional Portuguese Agriculture: Autecology in the study of ethnobotany}

of inspiring scholars to wonder how people are nice to plants, and how natural environmental forces may have participated in determining human fates. Neither of these is ecology in the strict biological sense; however, many recent works do implicate aspects of biological ecology in its application in the broader sense. Orlove and Brush (1996) review anthropological studies related to conservation ecology. Little (1999) reviews anthropological studies concerned with environmentalism. Balée (1998) reviews historical explanations implicating ecology. However, some ethnobotanical studies have considered a particular abiotic factor as a determinant of plant presence and abundance, and thus come closer to taking, more explicitly, an autecological approach. Some of the works of Harley Harris Bartlett through the middle of the 20th century (reviewed by Voss 1961) concern the impact of fire. A more recent review of the relationship among fire, human activities, and plants is provided by Crutzen and Goldhammer (1993). Asch and Asch (1978) describe the prehistoric disappearance of cultivated varieties of Iva annua L. (Asteraceae) from central U.S.A., where it had been domesticated by native Americans, during which human medicated evolution its dependency on water was probably altered. Nabhan (1985) presents more recent studies of traditional people and plants where water is a factor. Dzerefos et al. (1995) studied both the water and the soil fertility requirements of a traditional food plant.

\section{Illustration of an Autecological Perspecitive in Ethnobotany}

In my own work to understand how traditional agriculture has been practiced by the peasants of the mountainous interior of Portugal, I have drawn on the scholarship of my predecessors in each of the disciplines mentioned above, while using the concepts and methods of a biological plant ecologist. Here I present an autecological approach to the study of a human use of a plant.

\section{Ethnographic Setting}

The Parish of Cabril, Portugal contains several villages and village clusters, such as Ribeiros (Figure 1). The people here practiced subsistence agriculture until 1993. Commercial, fossil-fuel-driven agriculture never replaced their traditional (pre-fossil-fuel) practices, which diminished as the younger folks moved away and the older folks themselves died. A fire in 1993 discouraged the few remaining practitioners so that now only a few door-yard vegetable gardens remain. As you view Figure 2, you can readily see why this region did not attract commercial agriculture. Its soft shale hills on the western foothills of the Serra de Estrela, the highest range of mountains in Portugal, are eroded into deep, steep-sided valleys. The more level ridge tops are covered with thorny heath and legume shrubs growing in very shallow soil or on virtually bare rock outcrop. The steep hillsides are stepped with terraces, rib- bons of more level land five to ten meters wide held up by stone walls one to three meters high and built without mortar. Tiered in sequences of up to 20 or 30 , these terraces have been built onto the steep hillsides where ever it is possible to irrigate them with the water that seeps out of the porous shale rock during the hot, dry summer.

Fertile cultivated soil that has been prepared by the peasants themselves is held level and in place by these soilretaining walls, which serve important water control functions as well. Beginning in October of a typical year, rains fall almost daily until March, delivering one to one-and-ahalf meters of rainfall during the cool winter. Some of this water soaks into the shale rock and seeps out again later in the summer. Much of it runs over the surface, swelling in torrents that rush down the valley bottoms from December to April. Terraces are designed to conduct the winter water from terrace to terrace in a way that slows its speed, dissipates its energy, and keeps it away from the carefully created soil that they hold, so that soil loss by erosion will be minimal. The same terrace design allows the summer irrigation water to be conducted over the soil to soak in and hydrate the cultivated crops. There are hundreds of kilometers of soil-retaining walls in these hills. The untold story of the evolution of their functional design, the engineering of their construction, their maintenance, and the cultural traditions that codified and informed this technology in a society of illiterate peasants still awaits discovery.

I began studying the agricultural technology within the traditional peasant culture of the parish of Cabril during a brief stay in 1984, and continued in 1987 when I lived for five months in the village of Malho, in the village cluster of Ribeiros. Not one of the many area residents I have talked with has any memory of soil-retaining walls under construction, including an 84-year old stone mason, who was born in Cabril and lived there his whole life, practicing his trade. Thus, in any place where it was feasible to build a cultivated terrace, one had already been built by the early 20th century, if not long before. Estabrook (1998) and Vincente (1995) both present evidence to suggest that all the villages in this area were at or above their human carrying capacity by the middle of the 20th century. For centuries, the Catholic priest was the only literate resident of the parish. Written church records for this region are available, which date back to the mid-17th century. All of the villages named in 1987 were already named in these records by the mid-17th century. In 1308, Dom Dinis, the king of Portugal, awarded this area as a feif to a nobleman. At that time, this gesture would have been virtually worthless if the land had no residents, which suggests that it was at least partly inhabited. These factors combine to suggest that terraces were built wherever they could be irrigated, and that virtually all of them were already built long ago.

In their conversations with me in 1987 and 1991, residents recalled their young adulthood when they labored on these terraces with their traditional technology, un- 

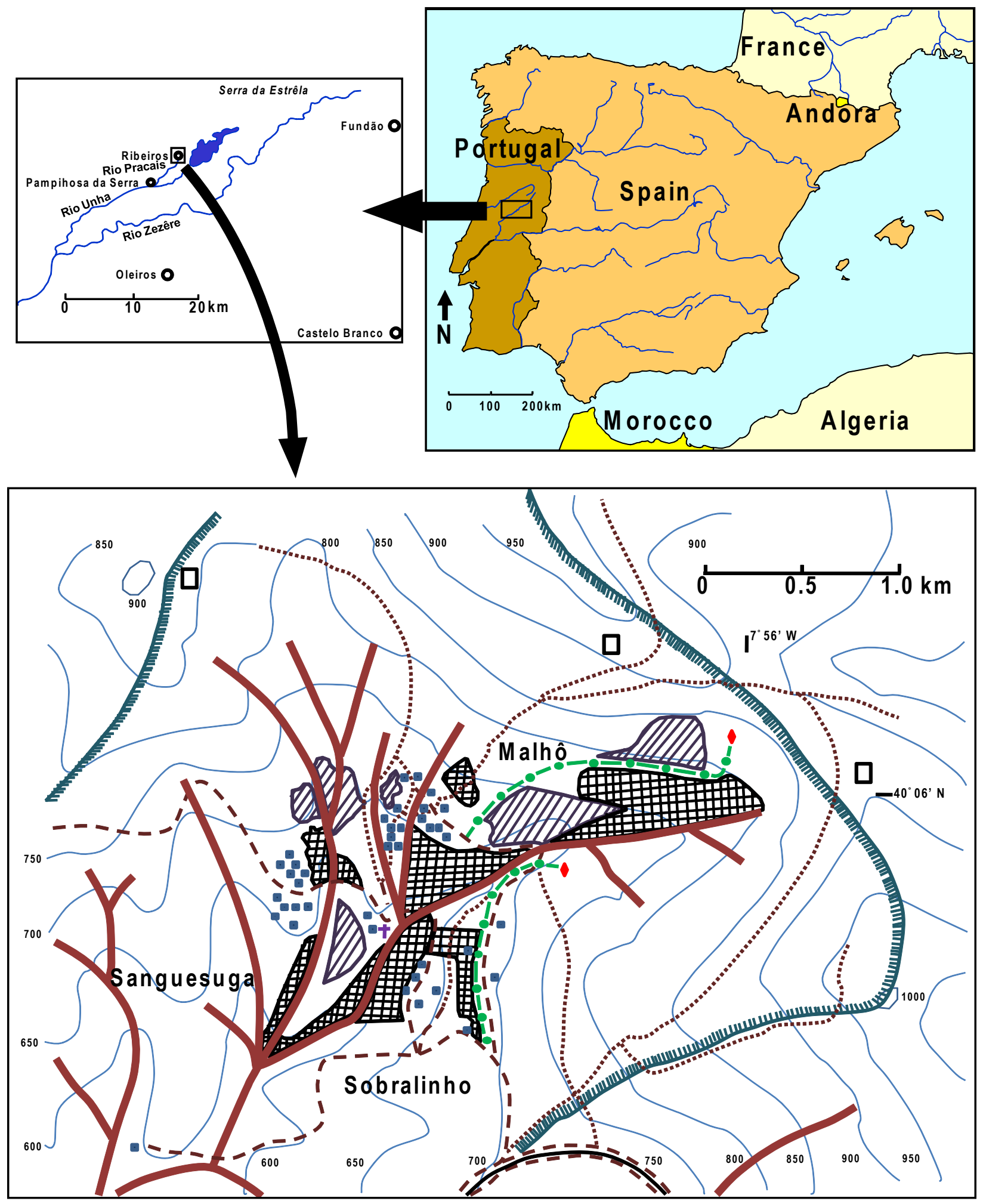

Figure 1. Location of Ribeiros at the headwaters of the Rio Pracais on the Western foothills of the Serra da Estrela Portugal. Solid squares are houses, cross-hatched areas contain terraces actively cultivated in 1993, lined areas are recently abandoned terraces, the 2 diamonds indicate the two principal irrigation water sources, and the lines of alternating dots and dashes leading from them indicate the course of the principal irrigation ditches. 


\section{Estabrook - Living Grass Irrigation Ditches in Traditional Portuguese Agriculture: Autecology in the study of ethnobotany}

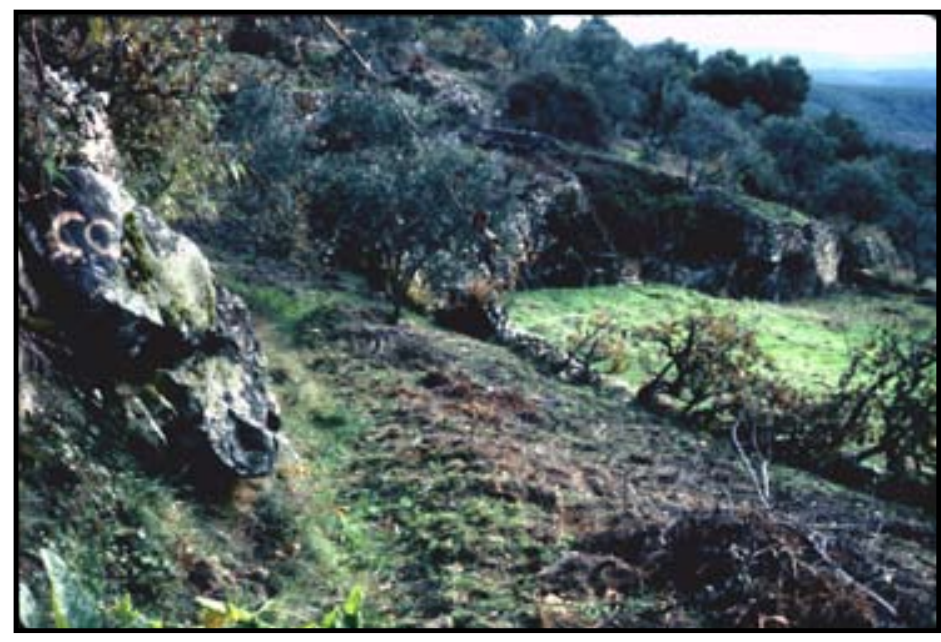

Figure 2. Contoured terraces in Val Pasqual; between curving soil retaining walls and a thick grass strip runs an irrigation ditch evident in the lower left; the continuing grass strip is visible right center as darker green at the base of the wall.

aware of the cultural demise that would await their final years. "All of this was cultivated and planted," they would often tell me, gesturing to the terraces, then already $80 \%$ or more abandoned, with only a few plots still cultivated by old folks (Figure 3 ). When I returned in 1993, I could see that a fire had burned the heath lands, destroy- ing much of the ecological resource on which this agricultural system depended. By academic year 1997-1998, which I spent as a visiting professor in the Department of Anthropology of the University of Coimbra, only two households still attempted any garden plot cultivation. At this point I believe they performed this labor more from a desire to celebrate their culture, which gave them identity and their lives meaning, than to realize economic returns.

By contrast, the people who left this region for the cities three or more decades ago, have raised their children to young adults, imbued with warm feelings for their ancestral village, but ignorant of the culturally informed technology of their ancestors. Now these young adults return for a few weeks a year to "fix up" their newly inherited grandparents' holdings for holiday visits. Their bungling alterations function as experimental manipulations. These result in autecological evidence that reveal to me some of the more invisible aspects of their ancestors' culturally codified technology.

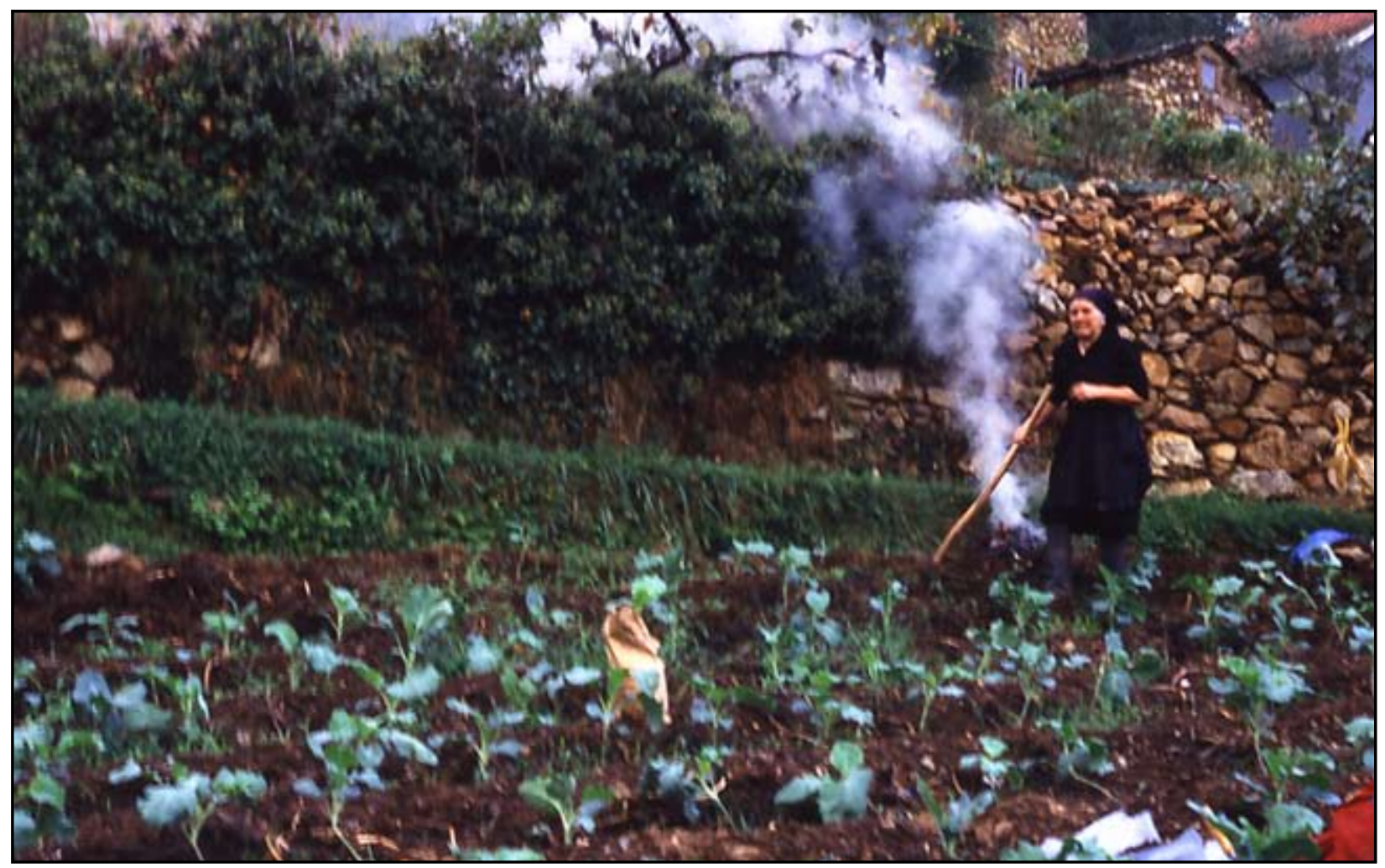

Figure 3. Resident of Malho cultivating a terrace near the village. Traditional stone houses are evident in the top right. Note the line of thick green vegetation along the base of the soil retaining wall. 


\section{The Terraces of Malho}

Rising about a kilometer to the east of the village of Malho is a small stream that runs down its steep valley, called Val Pasqual by the local people, and past the village to coalesce with several other small streams at a place called Ribeiros. These give rise to the Pracais River, a larger stream that flows another 15 kilometers down to Pampilhosa da Serra, now the county seat. The north-facing south side of Val Pasqual is a steep shale outcrop, partially covered with legume and heath shrubs, and a few chestnut trees near the stream bed. Before Malho was settled, the south-facing north side probably hosted natural vegetation, but now it is covered with about 20 soilretaining walls, one above another, 5 to 15 meters apart. Built to take advantage of natural curvatures of the rock face, these walls support the terraces on which residents have cultivated much of their food. This slope was attractive for cultivation of crops not only because of its sunny southern exposure, but also because, during the dry summer, copious water seeps out of the shale rock a few hundred meters up the valley, whence a small ditch conducts the water to irrigate the cultivated crops. The suitability of this slope for cultivation may explain why the village of Malho is where we find it today. Irrigation water travels a long distance either over exposed rock outcrop, sometimes for tens of meters, or along rock outcrop at the base of soil-retaining walls. When water moves in these ways, it is held in its path by a ribbon of grass that grows on the surface of the rock outcrop along the downhill side of the water course (Figure 4). This ribbon is a tough mat of rhizomes, myriad fine roots, and trapped organic matter 10 to 20 centimeters high but rarely more than 15 or 20 centimeters wide, which attaches itself to the shale outcrop. Thus, the irrigation ditch is made of rock outcrop on the uphill side, and a ribbon of living grass mat on the downhill side. Behind one soil-retaining wall, the soil surface of the terrace extends to the base of the next wall, where the soil becomes very shallow and then absent.

Water moves from one terrace to the terrace below, in one of two ways: Down stone-lined stepped cascades built into the retaining wall, about every hundred meters or so, to allow water to move to the next lower level without eroding soil, and to allow people to climb more easily from one level of terrace to the next (Figure 5); or down through the soil where it collects in specifically constructed drainage tunnels that conduct it under a lintel and into a small impoundment at the base of the retaining wall to be released again to irrigate the next terrace (Figure 6).

\section{A Pattern of Presence and Absence}

The major irrigation ditches that carry water all year round from its source a few hundred meters up the valley, or from the most faithful springs within the terrace system itself, have ditch grass on their lower side where they pass over rock outcrop. When such a major irrigation ditch runs

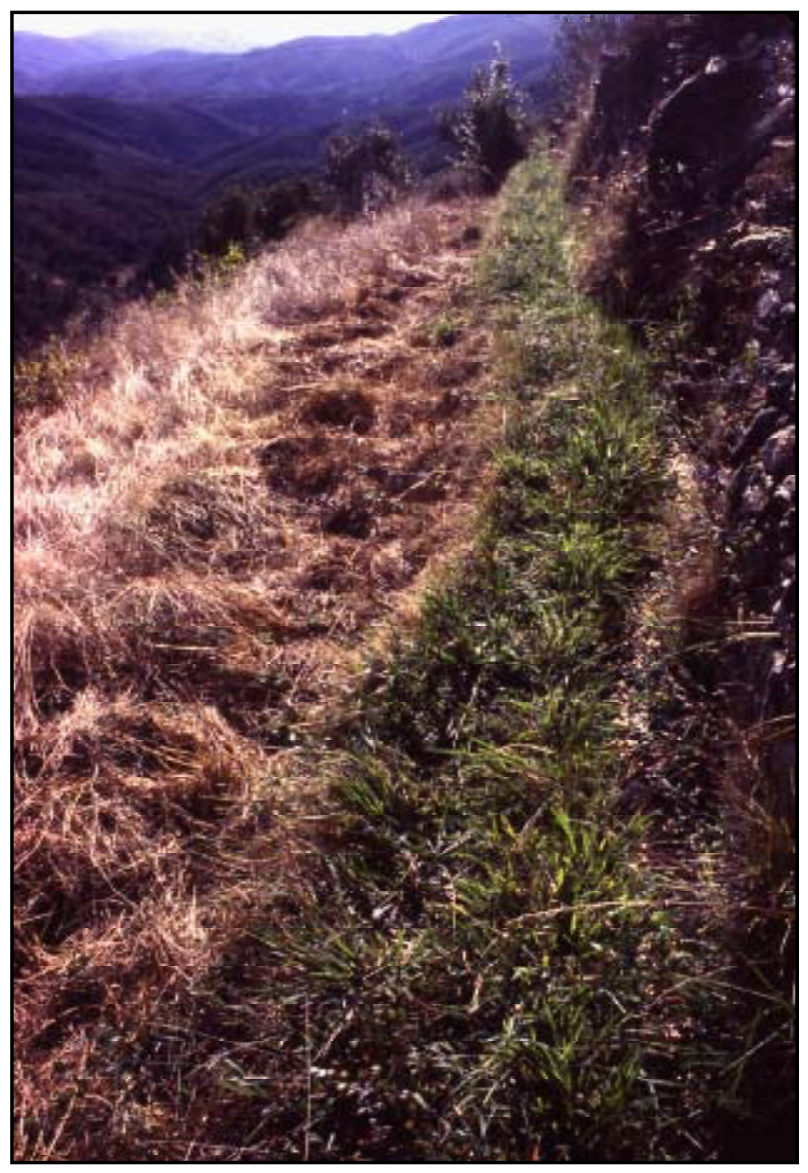

Figure 4. Irrigation water running from its source to the terraces of Malho. It is directed along its path at the base of a rock outcrop by a ribbon of living grass mat on its downhill side.

along a terrace, it follows the outcrop at the base of the wall above, with a ribbon of ditch grass mat holding the water in place (Figure 7). The cultivated soil extends out from this mat towards the valley to the top of the next retaining wall below.

In the drier summer season, corn, beans, cabbage, or onion (some common cultivated staples) are grown under irrigation on these terraces. During the time intervals each week when a farmer has the traditional right to divert water from the irrigation ditches onto his or her cultivated terraces, little ditches are created and destroyed with a hoe to direct water over the terrace and among the plants. This results in frequent weeding and cultivation by hoe of the soil around crops, which could easily eliminate all but the most aggressive unwanted plants. I never observed ditch grass growing in this cultivated soil.

At the beginning of the rainy season, a rye grass was sometimes planted in the soil of a terrace. Rye grass is grown with water constantly running through it, which prevents it from freezing during the frosts that occur a few 


\section{Estabrook - Living Grass Irrigation Ditches in Traditional Portuguese Agriculture: Autecology in the study of ethnobotany}

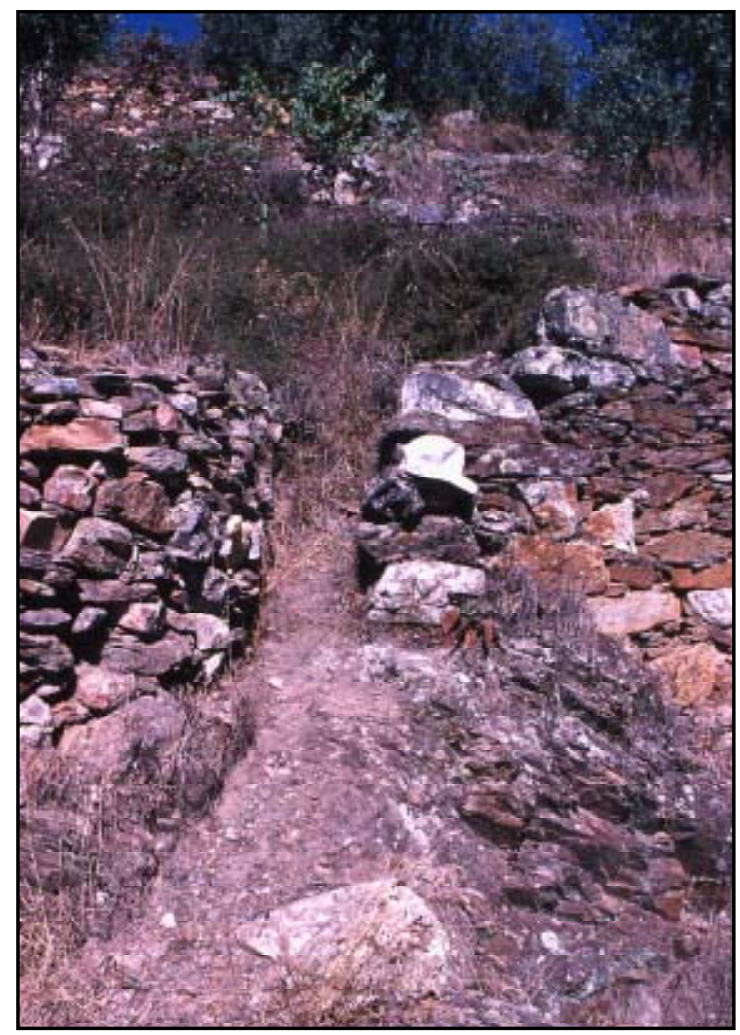

Figure 5. Traditional soil retaining walls takes advantage of rock outcrop to enable excess water to cascade to next lower terrace without eroding soil, and to allow people to climb more easily from one terrace to the next.

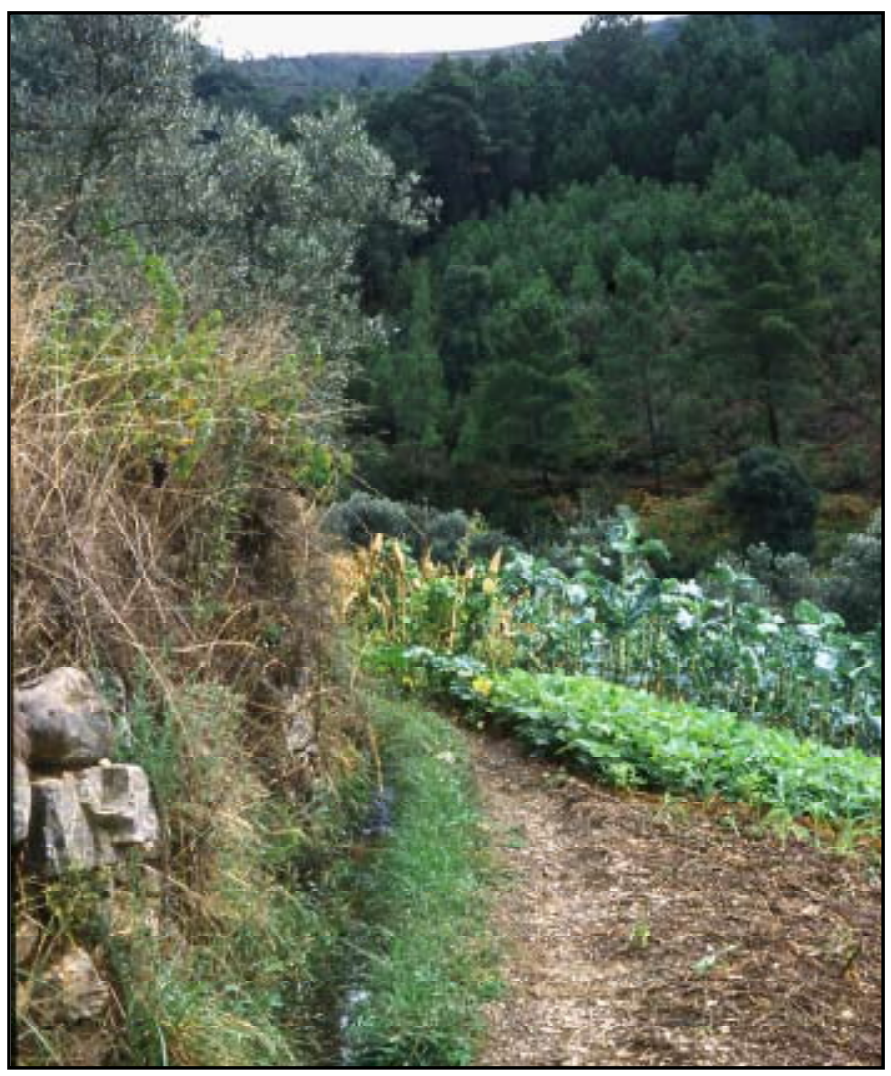

Figure 7. Cultivated terrace; between the base of the soil retaining wall and a strip of thick grass is a small irrigation ditch in which water flows over bedrock and is held in place by the living grass strip.

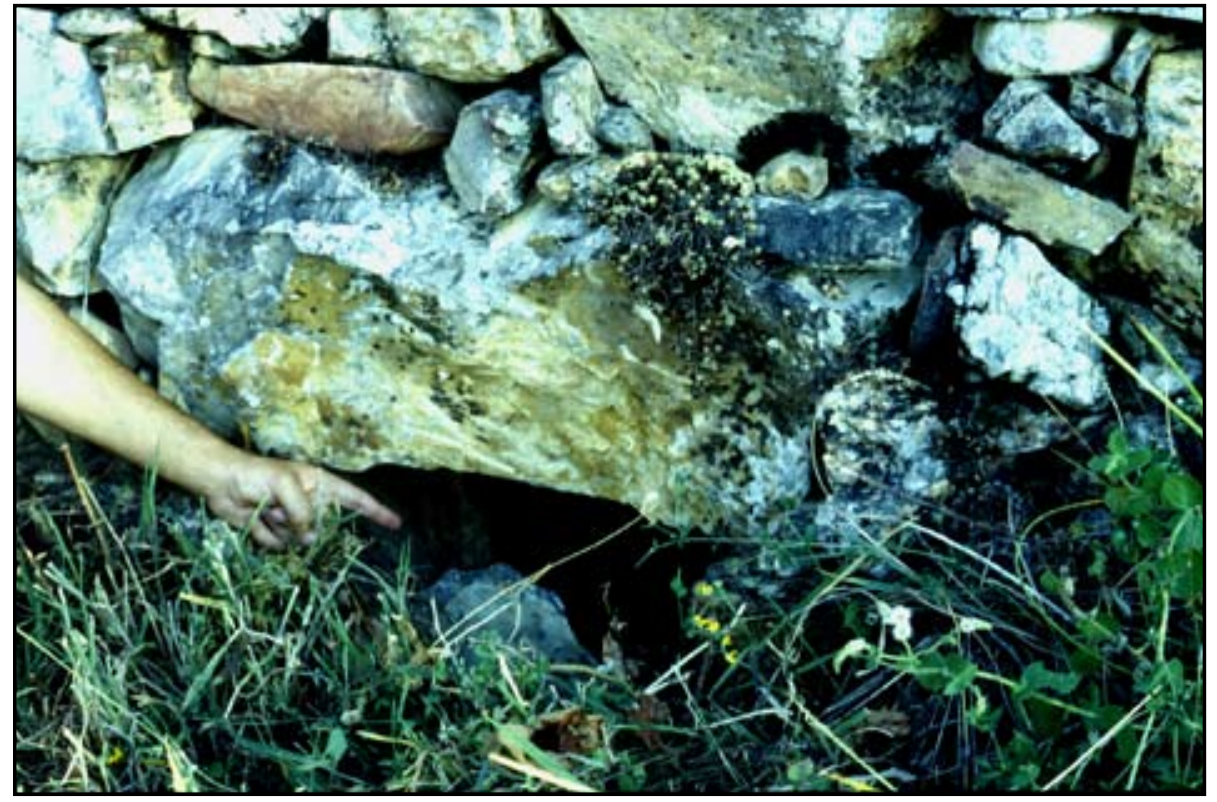

Figure 6. Larger quartzite rock near base of soil retaining wall serves as lintel to allow irrigation water that has filtered through the soil of the terrace above and collected against the bed rock to emerge at the top of the terrace below to reuse for irrigation. times each winter, and directs some of the copious water away from the stone cascades that are designed to conduct water down through the terraces with a minimum of soil erosion. The rye grass helps hold the soil in place, and periodically is cut about three inches above the ground with a sickle and given to oxen. People in Malho have not kept oxen since the early eighties when an older resident was killed by one, so much less rye grass was planted than formerly during the decade of my observations. I never observed ditch grass growing in the remaining cultivated rye grass, even though for six months of the year it is undisturbed and wet. 


\section{An Ecological Question in an Ethnobotanical Study}

Near the village of Malho, ditch grass occurs only in dense rhizomatous mats bordering the lower side of the major irrigation ditches that carry water all year round where they pass over rock outcrop on their way to, or in, the cultivated terraces. Having established this pattern, we now have an ecological (in the strict biological sense) question, "What explains the absence, presence, and (where it occurs) abundance of ditch grass?".

During the past decade, I have been on these terraces in all seasons of the year, with the immediate purpose to study how the peasants who cultivate them maintain the fertility of their soil with their pre-fossil-fuel technology, but I did not notice the function of ditch grass until 1997. The people who cultivate the terraces do not plant it and they do not harvest it, so they do not actively perceive it as "used". They never offered to show or explain it to me, even though they readily showed and described plants that they ate, used for forage or for the production of honey by bees or to make medicines. When it became more clear to me that these grass mats had an important if somewhat unusual use, I asked about them specifically.

Ditch grass does not seem to have a special name; it is called simply erva, which means a naturally occurring low, herbaceous plant. The word erva is used in this part of Portugal in a way that can be compared with two other words that mean low grass-like plants: Grama and relva, neither of which is applied to ditch grass. The term, grama, refers to a grass-like plant that grows low to the ground, but with connotations of being prejudicial to other more desirable plants. The term, relva, means a cover of grass-like plants, but with connotations of decorativeness or attractive physical appearance, e.g., a lawn. Ditch grass is not considered a weed. Weedy plants are often named for the crops they infest. For example, milhô, with its second syllable accent, is the name given to the annual weed Digitaria sanguinalis (L.) Scop. because it germinates in the cultivated corn, which is milho, with a first syllable accent.

Since many plants (often but not always grasses) are called erva, this name suggests that the peasants do not need to distinguish ditch grass and so may not deal with it consciously in their tradition. Peasants try neither to encourage nor to remove ditch grass, but in the unlikely event that the tough, resilient mat might be ripped away from its place, they would certainly put it back, much as they would replace a stone in the unlikely event that it got knocked off one of the dry masonry soil retaining walls that create the terraces. In this sense, ditch grass seems to be considered another permanent part of the terraces. Considering these ethnological factors and the past few hundred years of local human history, we can look for physical factors interacting with the adaptations of the plants themselves, to try to answer our ecological question.

\section{What Taxa Comprise Ditch Grass?}

Based on size, habit, vestiture, and persistence of firstformed leaves, the grass mat seems to consist principally of two species. I have been on the terraces of Malho many times of year for many years, and I have never seen either principal species in flower or fruit. Thus, none of my collections of them includes flowers or fruits. Lack of fruits or flowers makes any plant more difficult to identify, but in the case of most grasses virtually impossible. Some progress can be made with uncertain identities. For example, Ambrosoli (1992) presents an excellent historical study in which the identities of the economic plants mentioned in historical documents were often in doubt. However, it is very valuable to be able to identify plants studied ecologically. Herbarium collections and plant systematic studies, which have been accumulating over the past few hundred years, contain a vast amount of information potentially useful for evaluating ecological explanations for the presence and abundance of plants, even in ethnographic settings. When plants are identified, information about their adaptations, geographic locations, relationships with human beings, and about who has studied them and how to find other related published works, becomes much more accessible. Although the two grasses that constitute the principle fractions of the mat that serves to hold irrigation water as it passes over rock outcrop seem to rarely flower in that habitat, I wanted to attempt to induce them to flower so they could be identified.

In late April 2000, I mailed four living rhizomes of each of the two grasses to the United States Department of Agriculture (USDA) who forwarded them to the Herbarium of the University of Michigan in early May 2000, where they were grown in a growth chamber in quarantine until April 2001 when they were either autoclaved or made into dried, sterilized specimens. The rhizomes were grown in peat in $15 \mathrm{~cm}$ diameter pots under full spectrum lights at an intensity of from 1.5 to $2.5 \mathrm{~K}$ foot candles, with a 12 $\mathrm{hr}$ light-dark period at a constant $22^{\circ} \mathrm{C}$. They were watered copiously with tap water until growth appeared in about three weeks, when watering continued with high nitrogen, phosphorus and potassium (NPK) enriched tap water. Two of the courser featured plants and one of the finer featured plants were still growing in mid summer but showing signs of $\mathrm{Mg}$ deficiency, $\mathrm{So} \mathrm{MgSO}_{4}$ was also added to the regular irrigation water. By the end of the summer the finer featured plant had died but the two coarser featured plants were growing vigorously. On 20 Oct 2000 one plant was removed from its pot, and transplanted into a flat $60 \times 20 \times 5 \mathrm{~cm}$ by breaking up and spreading out its root mass. At this time day-length was reduced to $8 / 16$ $\mathrm{hr}$ with corresponding temperature $20 / 10^{\circ} \mathrm{C}$. Vigorous growth continued under high water and high nutrients. On Dec 5, day-length was shortened to $6 / 18 \mathrm{hr}$ with tempera- 


\section{Estabrook - Living Grass Irrigation Ditches in Traditional Portuguese Agriculture: Autecology in the study of ethnobotany}

tures reduced to $15 / 4^{\circ} \mathrm{C}$ until 15 Jan 2001 when $8 / 16 \mathrm{hr}$ and $18 / 8^{\circ} \mathrm{C}$ was initiated. On 1 Feb 2001 nutrients were stopped but watering with copious tap water continued. On 3 March, the beginning of culm growth was noticeable and $10 / 14 \mathrm{hr} 22 / 12^{\circ} \mathrm{C}$ was initiated. By early April, the flat contained a mat so thick and tough that it had to be cut with branch pruning shears to make specimens, and over 20 culms were in full flower. It was identified clearly as Festuca arundinacea Schreber. The species that died has not yet been identified.

F. arundinacea occurs widely in Europe, where it is reported to occupy damp grassland, stream and river banks, and sea shore (Tutin et al. 1980). A few decades ago, it was brought to the United States where it is used to stabilize road cuts after highways have been built. In this role in the USA, it exhibits a broad ecological niche with respect to tolerance of dry as well as wet conditions, freezing as well as heat and direct sunshine. It survives in low-nutrient, sandy soil typical of road cuts, and now rock gardeners in the USA consider it an invasive alien pest. The genotype of $F$. arundinacea that is a constituent of the ditch grass mat on the terraces of Malho seems to lack this broad niche and these invasive qualities in that habitat. However, rapid evolution of ecotypes in the USA does indicate that $F$. arundinacea may have been capable of rapid evolutionary change in the presence of human modifications of local conditions in Malho.

\section{Ecological Experiments}

To better understand the factors that explain the presence and absence of a plant, an autecologist would perform experiments: Manipulate conditions and observe how the plant in question responds. As an observer of a traditional people who depend on the use of their cultivated terraces for their livelihood, I cannot manipulate their resources without their express consent and co-operation. The residents had been so generous and tolerant of me that I was reluctant to ask for additional license, especially when the celebration of their lives depended on the continued access to their traditional practices.

Inheritors, whose parents as young adults had abandoned village life more than a generation ago for foreign or urban opportunities, are now in possession of their grandparents' holdings, including village dwellings. To provide running water to these dwellings for use during their brief holiday occupation, some of these new owners used plastic tubes to divert irrigation water from the formerly cultivated terraces to the village, where they filled sinks, baths and toilets, and drained or flushed them inappropriately into the streams that flow through the village. This polluted the water available to the downstream villages instead or maintaining the fertility of the local soil. In nearby villages with larger populations of year-round resident subsistence farmers, the invasion of these uncultured inheritors has resulted in violence and distress. In Malho, the 23 full- time residents who remained in 1987, of whom 12 were still actively farming in 1991, tolerated this disruption less desperately.

Unwittingly, these inheritors performed the kinds of manipulations that I had been reluctant to do myself. Some removed a piece of the grass rhizome mat above one of their inherited (but no longer cultivated) terrace plots to divert the irrigation water into a small impoundment from which they could drain it in plastic tubes down to the village. In 1991 and 1993 I saw that these manipulations had happened, but it was not until October 1997 and May 2000 when I revisited these terraces to collect plants, photos and data, that I observed their consequences.

Ditch grass mats on rock outcrops downstream from the few sites of former mat removal and water diversion were still present in some places, but dry and dead. In other places, owners (resident or inheritor) who had wanted the water to be able to flow again (or still) had removed the dead grass mat and constructed a little concrete wall in its place.

On the formerly cultivated terraces themselves, years of succession unchecked by cultivation on abandoned plots had transformed the vegetation. On these terraces, successional vegetation varies greatly from plot to plot, often dominated by silvas (Rubus), estevas (Cistus), or giestas (Cytisus) but never ditch grass.

This evidence suggests that the continued existence of the ditch grass mat depends on the near constant supply of water all year round and especially in the dry season. Where the flow of irrigation water was interrupted by "experimental" removal, the ditch grass exposed downstream on now dry rock outcrop, dies in the hot dry summer. Where water is led with its help over bare rock, even steep extended stretches, these ribbons of living grass rhizomes and roots function especially well, maintaining themselves only where the water flows, collecting detritus to make a nearly impermeable lower ditch side, clinging firmly to the rock surface but flexibly enduring the high volume water flows of the rainy winter. Ditch grasses do not substantially appear in the successional vegetation of the terraces when cultivation ceases so it seems unlikely that it is among the weedy grasses formerly mentioned that were repeatedly excluded from the terraces by cultivation practices. Ditch grasses may be so competitively inferior in soil that they are restricted to rock outcrop where the two predominant kinds share dominance, even without the selective disturbance of human cultivators. If indeed they rarely do flower in this habitat, this would greatly reduce their dispersal capabilities making it difficult for them to spread rapidly if at all from their established rock outcrop location, even if they were capable of growing in other nearby sites. 


\section{Speculative Scenario}

With these plausible autecological explanations, let us speculate on the state of ditch grass before humans inhabited this area. Then as now, it is likely that the winter rains soaked into the shale rock, or washed away in the rushing torrents what little soil may have accumulated during the dry summer but not have found the protection of a living plant. Not yet pressed into the service of humans who would construct irrigated terraces below them, naturally occurring seeps on the shale hillsides, and the banks of the streams, which fed by the seeps would likely have maintained at least a small stream of water during the hot dry summers, would be the natural habitats for ditch grass. Over the centuries as humans invested in their own habitat, all the small stream sides came to be walled to hold in the potentially destructive rushing water during the Winter and Spring, or cross-walled and backfilled to make cultivated terraces, and all the hill side seeps came to be excavated to make water mines to collect irrigation water for the terraces that had been constructed below them. Along the valley bottoms the streams are all walled (to prevent destructive flooding in late winter) with occasional minhos, which are mills that grind corn and rye seeds into flower, their stones turned from below by paddles that protrude into the rushing water, or lagares, which are mills that crush olive fruits, express the oil and wash the distasteful phenolics from it with boiling water, also powered from below by the rush of water. Thus, all the original natural habitat for ditch grass has been destroyed by people, who at first did not prevent, then came to allow, and perhaps more recently even to encourage ditch grass to inhabit, and now to be restricted to the habitat human economic activities incidentally created for it. In a few hundred or a thousand years it could have coevolved with people into an "ethnotype" that puts more of its resources into survivorship and vegetative reproduction and less into sexual reproduction, so that now it rarely if ever flowers. Although this scenario is clearly speculative, the ecological, evolutionary, organismal, ethnographic, and historical factors considered in this particular study simultaneously support its plausibility.

\section{Conclusions}

This study of grass irrigation ditches that perpetuate, because they grow where there is running water and in turn determine where there is running water, was revealed by the simultaneous awareness and practice of the principles and methods of both ethnobiology and ecology. This study illustrates several important ideas.

First, understanding ethnobiology can be greatly enriched by the inclusion of ideas and methods of ecology. Ethnobiology and its related discipline, economic botany, are potentially exciting and relevant subjects of modern study. Their practice has been burdened with disproportionate description and naming, with relatively little explanation. As a consequence, these disciplines are now undervalued by some practitioners of the more experimental sciences. The techniques, concepts and points of view of ecology can bring to bear not only sources of new data but also methods with which to hypothesize and test explanations that combine history and culture with natural science, to suggest exciting new understandings.

Second, plant-human interactions are one particular kind of plant-animal interaction, and thus a legitimate and fruitful subject of ecological study. Salick (1995) has pointed out that it is not much of a stretch to construe the study of economic botany as an example of the study of plant-animal interactions, a subfield of evolutionary ecology with a rapidly growing intellectual tradition. Similar arguments apply to ethnobotany. Clearly, interaction with human beings has had an enormous impact on the ecological properties of the plants humans actively cultivate. The present study suggests that humans may also have an impact on the ecology of plants they do not cultivate actively. More integration of ecology with ethnobotany would enrich ecology as well.

Third, there are some advantages to studying traditional cultures and technologies that may be still practiced by a few people, but that are otherwise severely invaded, contaminated, and disrupted by "modern" influences. Many of us who study cultural anthropology, ethnobiology, and related disciplines, may sense regret or loss as we see the cultures and technologies that we study break down, become contaminated or abandoned, and pass into history. Although this feeling is very understandable, the study I describe here demonstrates that some explanations are evidenced more clearly (or at all!) because the culture or technology under study is breaking down. We can take data from fortuitous "experiments" that would be professionally unconscionable to have performed ourselves, and in this way further our understanding, even as we regret their consequences. Thus, we can choose to try to preserve a culture even if its pure, original form has been contaminated by progress, and we can learn from the contamination things that we might never have been able to learn otherwise.

Fourth, there may be important, even vital, technical explanations for cultural beliefs and practices that appear to be "old wives tales" or have "only" ceremonial value. By virtue of their ecological requirements, limitations, and physical properties, the ditch grasses discussed here have performed their function as a natural part of a terrace system for many years, perhaps hundreds or thousands. The peasants and their ancestors, who have spent much of their lives working on these terraces, were no doubt aware in some sense that these strips of grass mat helped to keep the irrigation water in place, much as they might be aware that the walls help to keep the soil in place. Its presence must have been respected in order to ensure 


\section{Estabrook - Living Grass Irrigation Ditches in Traditional Portuguese Agriculture: Autecology in the study of ethnobotany}

the continuance of its service, which happened without human intervention as a consequence of its place in the local plant-human ecosystem.

The important cultural knowledge about this grass mat instructed people to NOT "use" it for anything but to leave it alone. Another example of an enhanced cultural reason to leave something alone for an invisible ecological reason is given by Itoh and Baba (1999), who present a study of the wild flowers of grassy embankments of terraced rice paddies in Japan. These authors describe Japanese traditional poetry, dating from before $760 \mathrm{AD}$ when it was compiled into a collection called Man'youshu, that extols the natural beauty of these grassy embankments. This poetry provides a cultural instruction to value these grassy embankments in their natural state and thus leave them undisturbed. Late 20th century disturbances of these grassy embankments have clearly revealed the importance of their function to control soil erosion and stabilize the terraces. Cultural beliefs and practices may preserve technology, but rarely in ways that explain it scientifically, instead often invisibly in ways that instruct its practice and ensure its preservation. This study of grass irrigation ditches suggests that functions of culture that are more important than explaining how or why technology works include: 1) Encode appropriate technology, so that it is inherited by the next generation as culture itself is inherited, 2) motivate its members to practice it in the right way and at the right time, and 3) preserve it from erosion by shortsighted, ignorant, or hostile forces. Estabrook (1994, 2000, and 2006) presents other examples of this idea. In these and in the present study, what reveals the relationship between culture and technology are the ecological concepts and methods implicated in the approach to studying the cultural practices.

\section{Vouchers}

Collections to vouch this study are at The University of Michigan Herbarium:

Estabrook 570 Festuca arundinacea Schreber;

Estabrook 571, 572, 573 indet.

\section{Acknowledgements}

Some of these ideas were presented as a talk to the XXII Annual Conference of the Society of Ethnobiology 11 March 1999 in Oaxaca, Mexico. I am grateful to the residents of Malho, Parish of Cabril, Portugal for their generous and trusting acceptance of me and for their willingness to talk to me about themselves. I appreciate the support of the following institutions and people: Portuguese Ministry of Agriculture and its laboratory of agricultural chemistry, LQARS; Archive of the Distrito de Coimbra, Portugal where I examined the Registro de Concelho de
Pampilhosa da Serra 1667-1889; The Herbarium of the University of Coimbra (Fatima Sales, collection manager) to dry and forward specimens; The Anthropology Department of the University of Coimbra, Portugal for welcoming me as a Visiting Professor in academic year 1997/8; The Luso-American Foundation for support in Portugal in 1998; Maria Antonia Rivas Ponce, Autonomous University of Madrid, Spain, and Gerrit Davidse, Missouri Botanical Garden, USA, for suggesting possible affiliations for my grass collections; $\mathrm{K}$. Brady of USDA for help to acquire USDA permit \#62712; Michael Frohlich for growing grass in quarantine in his growth chamber; and the many colleagues who criticized earlier versions of the manuscript. I am pleased to credit Debbie Hildebrandt with the creation of Figure 1.

\section{Literature Cited}

Ambrosoli, M. 1992. Scienziati, Contadini e Proprietari: Botanica e agricoltura nell'Europa occidentale, 13501850. Giulio Einaudi, Torino, Italia.

Asch, N. \& D. Asch. 1978. The economic potential of Iva annua and its prehistoric importance in the Lower Illinois Valley. Pp. 300-341 in The Nature and Status of Ethnobotany. Anthropological Papers No. 67. Edited by R.I. Ford. Museum of Anthropology, University of Michigan, Ann Arbor, Michigan, U.S.A.

Balée, W. 1998. Editor of Advances in Historical Ecology. Columbia University Press, New York, New York, U.S.A.

Crutzen, P.J. \& J.G. Goldammer. 1993. Editors of Fire in the Evironment: The ecological, atmospheric, and climatic importance of vegetation fires. Dahlem Workshop Reports, Environmental Sciences Research Report 13. John Wiley \& Sons, Chichester, U.K.

Daubenmire, R.F. 1947. Plants and Environment: A textbook of plant autecology. John Wiley \& Sons, New York, U.S.A.

Dzerefos, C.M., C.M. Shackleton \& M.C. Scholes. 1995. Seed germination, nitrogen nutrition, and water requirements of the edible herb Corchorus tridens (Tiliaceae). Economic Botany 49:380-386.

Estabrook, G.F. 2006. Neither Wild nor Planted: Essential role of giesta (Cytisus, Fabaceae) in traditional agriculture of Beira Alta, Portugal. Economic Botany 60:307-320.

Estabrook, G.F. 2000. How can we care for our old people and our children? Pp. 412-419 in Creating a Sustainable Future: Living in harmony with the earth. Edited by P.B. Kaufman. Research Book Company, New Delhi, India. 
Estabrook, G.F. 1998. Maintenance of fertility of shale soils in a traditional agricultural system in central interior Portugal. Journal of Ethnobiology 14:15-33.

Estabrook, G.F. 1994. Choice of fuel for bagaco stills helps maintain biological diversity in a traditional Portuguese agricultural system. Journal of Ethnobiology. 18:43-57.

Goodland, R. 1995. The concept of environmental sustainability. Annual Review of Ecology and Systematics 26:1-24.

Hoffman, C.A. \& C.R. Carroll. 1995. Can we sustain the biological basis of agriculture? Annual Review Ecology and Systematics 16:69-92.

Itoh, S. \& T. Baba. 1999. The Man'youshu anthology and the wild flowers of paddy field embankments. Curtis' Botanical Magazine 16:139-147.

Johnston, R.J., D. Gregory \& D. Smith. 1994. Editors of The Dictionary of Human Geography. Blackwell, Cambridge Massachusetts, U.S.A.

Joyal, E. 1994. Palm ethnoecology in the Saripiqui region of Costa Rica. Journal of Ethnobiology 14:161-172.

Krebs, C.J. 1972. Ecology: The experimental analysis of distribution and abundance. Harper and Row, New York, U.S.A.

Little, P.E. 1999. Environments and environmentalism in anthropological research. Annual Review of Anthropology 28:253-284.

Loomis, R.S. \& D.J. Connor. 1992. Crop Ecology: Productivity and management in agricultural systems. Cambridge University Press, Cambridge, U.K.

Moran, E.F. 1990. Editor of The Ecosystem Approach in Anthropology: From concept to practice. University of Michigan Press, Ann Arbor, Michigan, U.S.A.

Nabhan, G.P. 1985. Gathering the Desert. University of Arizona Press, Tucson, Arizona, U.S.A.

Orlove, B.S. \& S.B. Brush. 1996. Anthropology and the conservation of biodiversity. Annual Review of Anthropology 25:329-352.

Salick, J. 1995. Toward an Integration of Evolutionary Ecology and Economic Botany: Personal perspectives on plant/people interactions. Annals of the Missouri Botanical Garden 82:68-85.

Smith, R.L. \& T.M. Smith. 1998. Elements of Ecology. Benjamin Cummings, San Francisco, California, U.S.A.
Tutin, T.G., V.H. Heywood, N.A. Burges, D.M. Moore D.H. Valentine S.M. Walters \& D.A. Webb. 1980. Editors of Flora Europaea Volume 5. Cambridge University Press, Cambridge, U.K.

Vandermeer, J. 1995. The ecological basis of alternative agriculture. Annual Review of Ecology and Systematics 26:201-224.

Vincente, A.d.S. 1995. Vida e tradições nas aldeias serranas da Beira. Sograsul - Montijo, Portugal. Deposito Legal No. 84459 /95 Portugal.

Voss, E.G. 1961. Harley Harris Bartlett. Bulletin of the Torrey Botanical Club 88:47-56. 